\title{
ANÁLISE CRÍTICA \\ DE GÊNERO: UMA ANÁLISE \\ DE UM TESTE DE PROFICIÊNCIA \\ EM INGLÊS COMO LÍNGUA \\ ESTRANGEIRA
}

\section{ANÁLISIS CRÍTICO DE GÉNERO: UN ANÁLISIS DE UN EXAMEN DE PROFICIENCIA EN INGLÉS COMO LENGUA EXTRANJERA}

CRITICAL GENRE ANALYSIS: AN ANALYSIS OF A PROFICIENCY TEST IN ENGLISH AS A FOREIGN LANGUAGE

Patrícia Marcuzzo*

Amanda Petry Radünz**

Universidade Federal de Santa Maria

RESUMO: O objetivo deste trabalho é reportar uma Análise Crítica de Gênero (ACG) do Teste de Suficiência em Leitura em Língua Estrangeira (TESLLE). A análise textual incluiu seis edições do TESLLE de língua inglesa ofertadas entre 2014 e 2016, além de documentos oficiais. As questões foram classificadas em relação ao tipo e ao enfoque; e então em relação aos elementos da linguagem que acionam. A análise contextual foi realizada a fim de interpretar os dados obtidos. Os resultados apontam que as questões do teste são de três tipos e apresentam 12 enfoques. Além disso, as questões acionam quatro níveis da linguagem. A análise demonstrou 
que o teste realmente testa a habilidade da leitura, por acionar principalmente o nível da Semântica e da Pragmática, e que a visão de linguagem que subjaz o teste é de "linguagem como gênero", uma vez que a relação entre texto e contexto é explorada.

PALAVRAS-CHAVE: Análise Crítica de Gênero. Teste de proficiência. Leitura em língua estrangeira.

RESUMEN: El objetivo de este trabajo es reportar un Análisis Crítico de Género (ACG) del Teste de Suficiência em Leitura em Língua Estrangeira (TESLLE). El análisis textual incluyó seis ediciones del TESLLE de lengua inglesa ofrecidas entre 2014 y 2016, además de documentos oficiales. Las cuestiones fueron clasificadas con relación al tipo y al enfoque; y así entonces, con relación a los elementos del lenguaje que accionan. El análisis contextual fue realizado con el fin de interpretar los datos obtenidos. Los resultados apuntan que las cuestiones del examen son de tres tipos y presentan 12 enfoques. Además, las cuestiones accionan cuatro niveles del lenguaje. El análisis demostró que el examen realmente prueba la habilidad de lectura, por accionar principalmente el nivel de la Semántica y de la Pragmática, y que la visión del lenguaje que subyace el examen es de "lenguaje como género", una vez que la relación entre texto y contexto es bien explorada.

PALABRAS-CLAVE: Análisis Crítico de Género. Test de proficiencia. Lectura en lengua extranjera.

ABSTRACT: The objective of this paper is to report on a Critical Genre Analysis (CGA) of the Teste de Suficiência em Leitura em Lingua Estrangeira (TESLLE). The textual analysis included six editions of the English language TESLLE offered between 2014 and 2016, in addition to official documents. The questions were initially classified according to kind and focus, and then according to the language elements that they operate. The contextual analysis allowed the interpretation of the data. Results indicate that the test presents three kinds and 12 foci of questions. In addition, the questions operate four levels of language. The analysis showed that the test really assesses the reading ability because it operates mainly the level of Semantics and Pragmatics, and that the language view that underlies the test is "language as genre", considering that the relation between text and context is explored.

KEYWORDS: Critical Genre Analysis. Proficiency test. Foreign language reading

\section{INTRODUÇÃO}

Neste trabalho, enfocamos a análise de um gênero bastante conhecido no Brasil, pelos estudantes de pós-graduação. Geralmente ele é chamado de teste de proficiência e testa a habilidade de leitura em uma língua estrangeira. No caso deste trabalho, o enfoque é o Teste de Suficiência em Leitura em Língua Estrangeira, o TESLLE, da Universidade Federal de Santa Maria (UFSM), no Rio Grande do Sul. Na UFSM, o TESLLE é ofertado em duas edições por ano, sendo uma em cada semestre letivo, em cinco línguas estrangeiras: alemão, espanhol, francês, inglês e português para estrangeiros. De acordo com a resolução n. 003/10 (UFSM, 2010), que estabelece normas para realização do TESLLE na UFSM, os examinandos falantes de português podem inscrever-se no teste em alemão, espanhol, francês ou inglês, enquanto que os examinandos não falantes de português podem inscrever-se no teste de português como língua estrangeira (MARCUZZO, 2016, p. 2). O teste é ofertado nesta instituição exclusivamente para examinandos que tenham vínculo com a UFSM, sejam alunos de pós-graduação, servidores professores e técnico-administrativos em educação, e alunos de graduação prováveis formandos. Entretanto, os examinandos são principalmente alunos de pós-graduação que precisam comprovar a proficiência em leitura de textos acadêmicos em uma língua estrangeira para realizar o curso de mestrado, ou em duas línguas, para realizar o curso de doutorado.

O TESLLE de língua inglesa tem sido o mais procurado pelos examinandos, uma vez que cerca de 1200 examinandos realizam o TESLLE em cada edição, e destes, aproximadamente, 700 realizam o teste em inglês (MARCUZZO, 2016, p. 2). Isso ocorre provavelmente devido ao status do inglês como "língua da ciência", sendo a língua utilizada na maioria das publicações acadêmicas em diferentes áreas. Dessa forma, alunos de pós-graduação precisam ler textos acadêmicos nesta língua, e, portanto, realizam o TESLLE de língua inglesa (MARCUZZO, 2016, p. 2). 
Dada a importância dessa testagem no contexto da UFSM, pelo número crescente de examinandos a cada edição, o TESLLE de língua inglesa tem sido alvo de diferentes pesquisas no âmbito da instituição. Estudos prévios já investigaram os altos índices de erros dos examinandos no teste (WIELEWICKI, 1997); a relação entre os índices de erros e as áreas dos examinandos (BECKER, 2013); e os enfoques e as competências exploradas nas questões do teste (CUNHA, 2015). No entanto, pouco se sabe sobre o TESLLE de língua inglesa como exemplar de um gênero acadêmico-institucional.

Neste trabalho, buscamos relatar uma análise crítica do gênero TESLLE de língua inglesa com enfoque na análise contextual e textual. Com essa análise, em última instância, buscamos delinear a concepção de linguagem que subjaz esse teste.

\section{O TESLLE NO CONTEXTO DA UFSM}

O TESLLE de língua inglesa está inserido dentro de um contexto de testagem na esfera acadêmica, no caso, a UFSM. Nesse contexto, uma testagem é diferente de uma avaliação (MARCHEZAN, 2005, p. 27). A primeira é independente do ensino, tem objetivos próprios e não prevê contato entre o elaborador do teste e o examinando, sendo vista como o produto de um processo de aprendizagem (MARCHEZAN, 2005, p. 27). Nesse caso, há "uma distância entre o elaborador e o aluno", considerando que o examinando não pode “[...] adaptar a questão para seu estilo pessoal nem questionar o elaborador [...]” (WIGGINGS, 1993, p. 4). Isso significa que um teste somente objetiva testar o que o examinando sabe sobre o assunto que está sendo testado.

Por essas razões, muitos professores de línguas desconfiam de testagens (HUGHES, 1997, p. 4). Testes podem não ser o melhor tipo de avaliação para propósitos de ensino; entretanto, eles são necessários em muitas situações, como, por exemplo, no contexto acadêmico. De acordo com Hughes (1997, p. 4), "[...] informações sobre a habilidade linguística das pessoas são frequentemente muito úteis e algumas vezes necessárias”. O autor (HUGHES, 1997, p. 4) explica que esse tipo de informação é necessário para as universidades aceitarem alunos intercambistas, e para o conhecimento dos próprios examinandos. Exemplos de testes usados para propósitos acadêmicos são o Test of English as a Foreign Language (TOEFL) e o International English Language Testing System (IELTS).

Da mesma forma, o TESLLE é o teste institucional da UFSM que indica se o examinando está apto a ler textos acadêmicos em uma língua estrangeira. O termo "suficiência" tem sido adotado na instituição em vez de "proficiência" para adequar o nome dessa testagem ao objetivo e ao nível do TESLLE: identificar em que medida os examinandos conseguem ler satisfatoriamente ou "suficientemente" bem textos acadêmicos autênticos escritos em língua estrangeira.

Consideramos que o TESLLE se configura como um gênero, ou seja, é uma “[...] atividade[s] culturalmente pertinente[s], mediada[s] pela linguagem num dado contexto de situação [...]” (MOTTA-ROTH, 2005, p. 181) e, em vista disso, buscamos analisá-lo com base no enfoque teórico e metodológico da Análise Crítica de Gênero, que apresentamos na próxima seção.

\section{A ANÁLISE CRÍTICA DE GÊNERO}

No contexto do Brasil, a Análise Crítica de Gênero tem sido adotada em alguns trabalhos para descrever a linguagem em uso a partir da análise do texto dentro do seu contexto (ver, por exemplo, trabalhos como o de Motta-Roth e Marcuzzo (2010), Bonini (2010) e Soares (2016)). A Análise Crítica de Gênero usa o conceito de gênero como discurso em conexão com atividades sociais em contextos institucionais e "[...] se concentra na descrição, interpretação e explicação dos textos em seus contextos, a partir de um ponto de vista sócio-discursivo" (MOTTA-ROTH; HEBERLE, 2015, p. 26). 
A Análise Crítica de Gênero está ancorada em pelo menos três perspectivas teórico-metodológicas: a Sociorretórica, a Análise Crítica do Discurso e a Linguística Sistêmico-Funcional. "Da Sociorretórica, a Análise Crítica de Gênero se apropria da visão de como o gênero funciona dentro de instituições sociais (MOTTA-ROTH; HEBERLE, 2015, p. 26)”. A Análise Crítica de Gênero também incorpora a perspectiva tridimencional de Fairclough $(1989,1995,2010)$, que inclui texto, prática discursiva e o contexto mais amplo das práticas sociais (MOTTA-ROTH; HEBERLE, 2015, p. 26). Já a Linguística Sistêmico-Funcional é utilizada para realizar a análise da léxico-gramática em termos de funções da linguagem (MOTTA-ROTH; HEBERLE, 2015, p. 26). A Linguística Sistêmico-Funcional enfoca os "[...] elementos linguísticos e retóricos do texto [...] em combinação com [...] os elementos ideológicos do contexto" (MOTTA-ROTH, 2008, p. 370). Para analisar esses diferentes elementos no mesmo texto, Martin (1992) propôs a estratificação da linguagem, adaptada por Hendges (2005) e Motta-Roth (2008). A Figura 1 foi retirada de Motta-Roth (2008, p. 352).

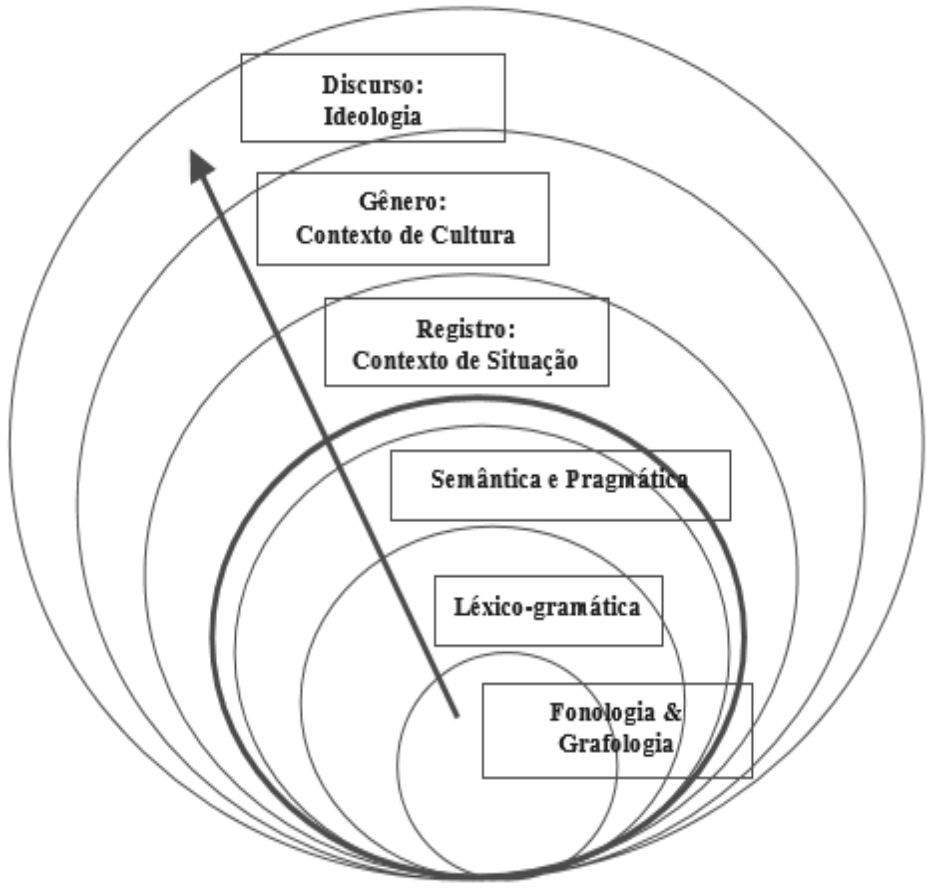

Figura 1: A estratificação da linguagem

Fonte: Motta-Roth (2008, p. 352)

Nascimento (2017) explica os conceitos por trás de cada estrato. De acordo com Nascimento (2017, p. 129), o estrato do Discurso ${ }^{1}$ lida com "a(s) ideologia(s), ou seja, as visões de como as 'coisas' deveriam funcionar". O estrato do Gênero enfoca os "[...] usos da linguagem em práticas discursivas relativamente estáveis e reconhecidas em uma cultura [...]" (NASCIMENTO, 2017, p. 130). De acordo com Halliday (1978) e Martin (1992), citados em Nascimento (2017, p. 130), no estrato do Registro, nós observamos como o contexto de situação fornece características específicas aos gêneros, fornecendo detalhes sobre o contexto do texto, as relações sociais envolvidas e sua organização. O estrato da Semântica e Pragmática observa a "configuração dos elementos linguísticos", respondendo às perguntas: "Qual aspecto da experiência humana está sendo construído no texto? Como é negociada a relação entre o autor e a audiência? Quais são os valores atribuídos à informação de acordo com a sua distribuição no texto?" (NASCIMENTO, 2017, p. 131). De acordo com Nascimento (2017, p. 131), para responder a essas perguntas, a análise do estrato da Léxico-gramática (na forma de grupos nominais, por exemplo) e da Fonologia e Grafologia é necessária. Dessa forma, a linguagem usa ferramentas de todos esses estratos e todos eles devem ser considerados em uma análise linguística.

\footnotetext{
${ }^{1}$ De acordo com Nascimento (2017), o uso das letras maiúsculas em Discurso, Gênero, Registro, Semântica e Pragmática, Léxico-gramática, Fonologia e Grafologia é uma convenção da Linguística Sistêmico-Funcional (HALLIDAY, 1978; MARTIN, 1992) quando eles referem-se a categorias de análise linguística.
} 


\section{METODOLOGIA}

Uma vez que a Análise Crítica de Gênero pressupõe a análise do texto e do contexto, neste trabalho, a análise do texto incluiu seis edições do TESLLE de inglês ofertadas entre o $1^{\circ}$ semestre de 2014 e o $2^{\circ}$ semestre de 2016, e a análise do contexto incluiu a análise documental, ou seja, documentos oficiais relativos ao TESLLE, conforme apresentaremos nesta seção.

A análise do texto incluiu ao todo 96 questões, que foram coletadas em seis edições do TESLLE (cada edição é composta por 16 questões). Os exemplares das edições do TESLLE foram solicitados à comissão responsável pelo TESLLE na instituição. Para identificação e posterior referência ao longo deste trabalho, as 96 questões do corpus receberam um código, o qual é composto por dois números separados por um hífen (-), uma sigla, um símbolo e outro número. Os primeiros números do código referem-se ao ano e ao semestre da edição do TESLLE: 14-1 refere-se ao primeiro semestre de 2014 e 14-2, ao segundo semestre do mesmo ano, e assim por diante. A sigla Q foi utilizada para se referir a palavra "questão", e o símbolo \# foi utilizado para designar o número da questão do teste (por exemplo: a primeira questão será representada pelo código: Q\#01).

No primeiro momento da análise do texto, as questões foram classificadas de acordo com seus tipos e enfoques. Medeiros (1997) fundamentou a análise acerca da classificação dos tipos das questões, a saber: completamento (ou de lacuna); certo-ou-errado (falsoou-verdadeiro, sim-ou-não, concordo-discordo); escolha múltipla (múltipla escolha); associação (correspondência, emparelhamento, combinação ou acasalamento); e ordenação (ou seriação). Becker (2003) e Cunha (2015) fundamentaram a análise dos enfoques das questões: acordo/desacordo; referência; conectores lógicos/relações oracionais; organização retórica (IMRD)/gênero; extração de informação do texto/identificação de informação no texto; resumo; identificação da formação textual; fato/opinião; transcrição de definição; modalidade; inferência; rotulação; metáfora; multimodalidade; e tradução (BECKER, 2013, p.12; CUNHA, 2015, p. 12-13).

No segundo momento da análise do texto, classificamos as questões de acordo com o estrato da linguagem que elas acionam. Halliday (1978) e Halliday e Hasan (1989) fundamentaram essa análise a partir dos níveis da linguagem nos termos da estratificação: Fonologia e Grafologia; Léxico-gramática; Semântica e Pragmática; Registro; Gênero; e Discurso.

Os dados textuais foram analisados qualitativa e quantitativamente. A abordagem qualitativa foi utilizada para classificar as questões nos seus tipos, nos enfoques e na estratificação e também para interpretar os dados, e a abordagem quantitativa foi utilizada para identificar quantas questões abordam cada tipo e enfoque e cada estrato da linguagem.

A análise do contexto incluiu a análise documental dos seguintes materiais do TESLLE:
1) o site do TESLLE (2018a);
2) a resolução n. 003/10 (UFSM, 2010);
3) o programa do TESLLE (2018b) e;
4) o minimanual do candidato (TESLLE, 2018c)

A análise contextual foi realizada a partir da leitura e releitura de documentos relativos ao TESLLE a fim de identificar informações relevantes para contextualizar e interpretar os dados textuais obtidos.

Neste trabalho, as três perspectivas teórico-metodológicas nas quais a ACG está ancorada ofereceram subsídios que fundamentaram todas as etapas da pesquisa, incluindo coleta, análise e interpretação dos dados. A Sociorretórica e a perspectiva tridimencional de 
Fairclough possibilitaram coletar e analisar os testes de suficiência como exemplares de um gênero, permitindo que fossem analisados dentro de seu contexto de produção e consumo, no caso, a UFSM. Já a Linguística Sistêmico-Funcional ancorou a análise textual. A próxima seção apresenta os resultados obtidos por meio desses procedimentos e suas interpretações.

\section{RESULTADOS E DISCUSSÃO}

A análise textual e contextual revelou que o TESLLE atual é formado por questões objetivas e um texto-base. Ao todo, são 16 questões escritas, sendo todas de múltipla-escolha, escritas em português (tanto o enunciado quanto as 5 alternativas de respostas) e acompanhadas por um texto-base escrito na língua-alvo, no caso, língua inglesa. Geralmente o texto-base não sofre alterações de layout nem recortes a fim de manter o texto no seu formato original. De acordo com o Programa do TESLLE, o tema dos textosbase não é específico a nenhuma área do conhecimento científico, como Saúde, Ciências Agrárias ou Rurais, já que o teste é destinado a examinandos de diferentes áreas do conhecimento. Se o teste explorasse exclusivamente a leitura de um texto-base da área de Saúde, por exemplo, os examinandos dessa área poderiam utilizar seu conhecimento específico para realizar o teste; e o objetivo comunicativo do TESLLE é testar conhecimentos de examinandos acerca da habilidade de leitura acadêmica geral em língua estrangeira, no caso língua inglesa, em nível intermediário, não conhecimentos específicos em uma determinada área do conhecimento. Portanto, o tema dos textos-base é geralmente comum a todas as áreas, como metodologia de pesquisa, plágio no contexto acadêmico, popularização do conhecimento científico, etc., conforme apresentado no Programa do TESLLE.

Nas 96 questões analisadas, identificamos três tipos de questão: 1) pergunta e resposta; 2) acordo ou desacordo; e 3) associação. O Quadro 1 exemplifica cada tipo de questão.

\section{Pergunta e resposta}

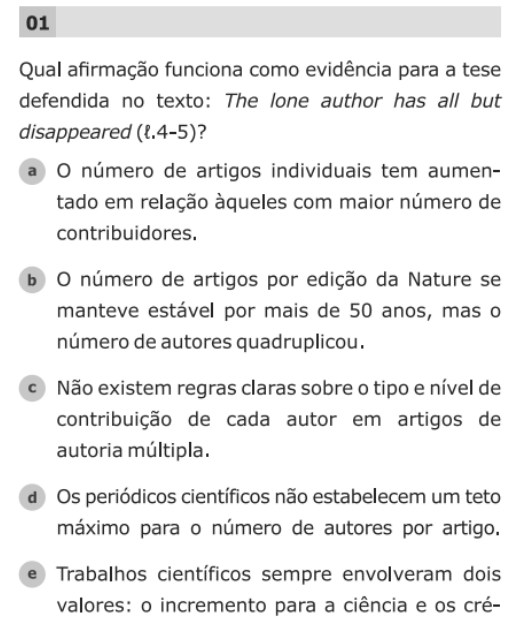

Qual afirmação funciona como evidência para a tese defendida no texto: The lone author has all but disappeared ( $\ell .4-5)$ ?

a $\mathrm{O}$ número de artigos individuais tem aumentado em relação àqueles com maior número de contribuidores.

b O número de artigos por edição da Nature se manteve estável por mais de 50 anos, mas o número de autores quadruplicou.

c Não existem regras claras sobre o tipo e nível de contribuição de cada autor em artigos de autoria múltipla.

d Os periódicos científicos não estabelecem um teto máximo para o número de autores por artigo.

e Trabalhos científicos sempre envolveram dois valores: o incremento para a ciência e os créditos pela descoberta.

\section{Acordo ou desacordo}

\section{5}

Indique se as afirmações a seguir estão em acordo (A) ou desacordo (D) com o texto.

( ) A razão pela qual não se especifica quem faz o quê em um artigo cientifico é a falta de pressão para tal especificaçăo (l.43-46).

( ) Os cientistas vão preferir receber pouco ou nenhum crédito por muitos artigos a receber crédito total por poucos artigos (l.128-129).

( ) É muito dificil acreditar que a divisão de trabalho seja igual entre todos os autores, quando se trata de artigos com 20 ou mais autores (l.37-42).

A sequência correta é

a D - D - D.

d $D-A-A$.

b $D-D-A$.

e $A-D-A$

c $A-A-A$
Associação

\section{2}

Associe as colunas de forma a indicar o que cad segmento está fazendo.

A - have we ceased to care? ( ) sugerindo (l.30-31).

$\mathrm{B}$ - as more and more areas of science - genomics, proteo( ) questionando ( ) exemplificando mics, climate modelling and particle physics are the most prominent (l.111-114).

C - interested parties could watch these pages to see whether a trend towards more restricted authorship is emerging (८.136-138).

A sequência correta é

a $\mathrm{B}-\mathrm{A}-\mathrm{C}$.

d $A-B-C$.

b $C-A-B . \quad$ e $B-C-A$

c $C-B-A$.

Quadro 1: Tipos de questão. 
O tipo mais comum de questão no TESLLE é o tipo pergunta e resposta, que apresenta uma pergunta (com um ponto de interrogação no final) e cinco opções de respostas, e o examinando deve escolher a resposta correta (ver o $1^{\circ}$ exemplo no Quadro 1). Essa definição de questão é muito similar a definição de Medeiros (1997, p. 53) para o que é chamado de "questões de múltiplaescolha"; entretanto, nomeamos esse tipo de questão de pergunta e resposta porque a análise mostrou que todas as questões do TESLLE são de múltipla-escolha, incluindo uma pergunta que pressupõe uma resposta.

Medeiros (1977, p. 45) também define as questões de certo-ou-errado como as que exigem que o examinando identifique as alternativas que estão certas e erradas. Estas foram classificadas como acordo ou desacordo, considerando que elas apresentam afirmações que o examinando deve identificar se estão de acordo ou desacordo com a informação apresentada no texto, então o examinando precisa escolher a alternativa correta de resposta.

As questões de associação foram definidas por Medeiros (1997, p. 79) como as que fornecem dois grupos de informação que precisam ser associados. Neste estudo, adotamos a mesma nomenclatura para o mesmo tipo de questão. Para responder essas questões, o examinando também precisa escolher a alternativa de resposta que apresenta a associação correta entre os grupos de informação.

Os resultados apontam que $74 \%$ das questões são do tipo pergunta e resposta, seguido de $15 \%$ do tipo acordo ou desacordo e $11 \%$ do tipo associação. Todas as edições do corpus deste estudo apresentam esses três tipos de questão.

Além dos tipos de questão, encontramos 12 diferentes enfoques no corpus, baseados nos estudos prévios sobre o TESLLE de Becker (2013) e Cunha (2015). As edições do TESLLE de 2014 a 2016 enfocam: 1) Advérbios - é esperado que o examinando identifique diferentes advérbios de tempo, modo e espaço; 2) Evidência textual - o mesmo que "identificação de informação no texto" por Cunha (2015, p. 12) - nessas questões, é esperado que o examinando identifique evidências textuais para responder o que está sendo perguntado; 3) Figura de linguagem - "metáfora” por Cunha (2015, p. 12) - é esperado que o examinando identifique a linguagem metafórica, ou seja, quando os autores usam uma palavra, expressão ou oração para se referir a outro significado que não o significado literal de uma palavra, expressão ou oração; 4) Funções de partes do texto - "rotulação" por Cunha (2015, p. 12) - é esperado que o examinando rotule alguns segmentos, considerando se eles estão sugerindo, questionando ou exemplificando; 5) Gênero - é esperado que o examinando identifique funções de diferentes partes do texto e/ou o propósito comunicativo do gênero; 6) Inferência - é esperado que o examinando infira e avalie o significado de frases específicas; 7) Modalidade - é esperado que o examinando identifique os diferentes níveis de modalidade em partes específicas do texto; 8) Multimodalidade - é esperado que o examinando identifique a relação da informação nas imagens (no texto não verbal) com a informação no texto verbal; 9) Referência - é esperado que o examinando identifique os referentes exofóricos, anafóricos e catafóricos de pronomes específicos, grupos nominais e pronomes, tais como "it", "we", "you”, "this", "the last of these", etc; 10) Relações oracionais - é esperado que o examinando identifique o tipo de relação entre as orações; 11) Tempos e vozes verbais - é esperado que o examinando identifique diferentes tempos e vozes verbais em inglês em orações específicas; e 12) Tradução - é esperado que o examinando traduza um trecho do texto em inglês para o português. No corpus, duas questões envolvem dois enfoques. Uma mistura evidência textual e modalidade, já a outra, evidência textual e multimodalidade.

O Quadro 2 mostra todos os enfoques, a ocorrência desses enfoques por edição e um excerto do enunciado das questões de cada enfoque, para exemplificação da análise. 


\begin{tabular}{|c|c|c|c|c|c|c|c|c|}
\hline \multirow{2}{*}{ Enfoque } & \multicolumn{7}{|c|}{ Número de questões } & \multirow{2}{*}{ Excerto } \\
\hline & $14-1$ & $14-2$ & $15-1$ & $15-2$ & $16-1$ & $16-2$ & Total $\%$ & \\
\hline 1- Advérbios & 0 & 0 & 0 & 0 & 1 & 0 & 1 & $\begin{array}{l}\text { "Considere os trechos a seguir [...] Os segmentos } \\
\text { sublinhados em I e II apresentam ideia de, } \\
\text { respectivamente" 2016-1 Q\#08 }\end{array}$ \\
\hline 2- Evidência textual & 4 & 9 & 9 & 9 & 10 & 8 & 51 & $\begin{array}{l}\text { “Em relação à lei de Lotka, considere as afirmações } \\
\text { a seguir [...] Está(ão) correta(s)" 2014-1 Q\#11 }\end{array}$ \\
\hline 3- Figura de linguagem & 1 & 0 & 0 & 0 & 0 & 0 & 1 & $\begin{array}{l}\text { "Considere os seguintes segmentos do texto: [...] } \\
\text { É(São) exemplo(s) de linguagem metafórica, ou } \\
\text { seja, linguagem figurada, para se referir à } \\
\text { progressão dos pesquisadores na carreira } \\
\text { científica” 2014-1 Q\#09 }\end{array}$ \\
\hline 4- Funções de partes do texto & 1 & 0 & 0 & 0 & 0 & 0 & 1 & $\begin{array}{l}\text { "Associe as colunas de modo a indicar o que cada } \\
\text { segmento está fazendo [...] A sequência correta é" } \\
\text { 2014-1 Q\#12 }\end{array}$ \\
\hline 5- Gênero & 0 & 1 & 2 & 1 & 0 & 0 & 4 & $\begin{array}{l}\text { "O texto está organizado, em termos de conteúdo, } \\
\text { em diferentes partes, as quais são" 2014-2 Q\#13 }\end{array}$ \\
\hline 6- Inferência & 1 & 0 & 0 & 0 & 0 & 0 & 1 & $\begin{array}{c}\text { "Com base no segmento [...], pode-se inferir:" } \\
\text { 2014-1 Q\#05 }\end{array}$ \\
\hline 7- Modalidade & 3 & 2 & 2 & 1 & 1 & 2 & 12 & $\begin{array}{l}\text { "Assinale a alternativa cuja afirmação revela alto } \\
\text { grau de certeza dos autores em relação ao que } \\
\text { dizem" 2014-2 Q\#12 }\end{array}$ \\
\hline 8-Multimodalidade & 1 & 0 & 0 & 0 & 0 & 0 & 1 & $\begin{array}{l}\text { "O segmento que melhor resume a imagem do } \\
\text { texto é" 2014-1 Q\#16 }\end{array}$ \\
\hline 9- Referência & 1 & 1 & 1 & 2 & 2 & 1 & 8 & $\begin{array}{l}\text { "Os segmentos destacados em [...] referem-se, } \\
\text { respectivamente, a" 2015-2 Q\#09 }\end{array}$ \\
\hline 10- Relações oracionais & 2 & 1 & 1 & 2 & 1 & 3 & 11 & $\begin{array}{c}\text { "Assinale o segmento que inclui uma relação } \\
\text { lógica de CAUSA-CONSEQUÊNCIA entre as } \\
\text { ideias" } \\
2015-1 \mathrm{Q} \# 07\end{array}$ \\
\hline 11- Tempos e vozes verbais & 0 & 0 & 0 & 0 & 1 & 0 & 1 & $\begin{array}{l}\text { "Os segmentos sublinhados em [...] (\$9) estão, } \\
\text { respectivamente, nos seguintes tempos e vozes } \\
\text { verbais:" 2016-1 Q\#07 }\end{array}$ \\
\hline 12- Tradução & 2 & 1 & 1 & 1 & 0 & 1 & 6 & $\begin{array}{c}\text { "O segmento [...] pode ser traduzido para o } \\
\text { português, sem alteração de sentido, como" 2014- } \\
1 \mathrm{Q} \# 04\end{array}$ \\
\hline
\end{tabular}

Quadro 2: Enfoques das questões.

Fonte: produzido pelas autoras.

Na maioria das questões o examinando precisa identificar a informação no texto (evidência textual, 51\% das questões), ou seja, a partir da questão, ele precisa realizar a leitura de alguma parte específica do texto para respondê-la. O segundo enfoque mais explorado pelo TESLLE (12\% das questões) é a modalidade, em que o examinando precisa identificar os graus de certeza que o autor 
do texto demonstra. Também se destacam as questões que enfocam relações oracionais (11\%), referência (8\%), tradução (6\%) e gênero (4\%), normalmente representando pelo menos uma questão por edição. Esses dados apontam que, no TESLLE, o examinando precisa lidar com diversos aspectos da linguagem para realizar a leitura do texto em língua inglesa, o que também foi confirmado na análise dos estratos da linguagem explorados pelas questões.

Entendemos que a identificação dos estratos da linguagem que as questões exploram pode não ser muito clara, considerando que a linguagem é o conjunto de todos os níveis juntos. Dessa forma, para entender um texto, então o examinando ativaria o conhecimento de todos eles para resolver a questão. Entretanto, consideramos qual estrato da linguagem é mais enfatizado ou "acionado" para a resolução da questão. Nas seis edições analisadas neste estudo, as questões exigem do examinando o conhecimento dos estratos da Léxico-gramática, da Semântica e Pragmática, do Gênero e do Discurso. O Quadro 3 exemplifica cada estrato nas questões.

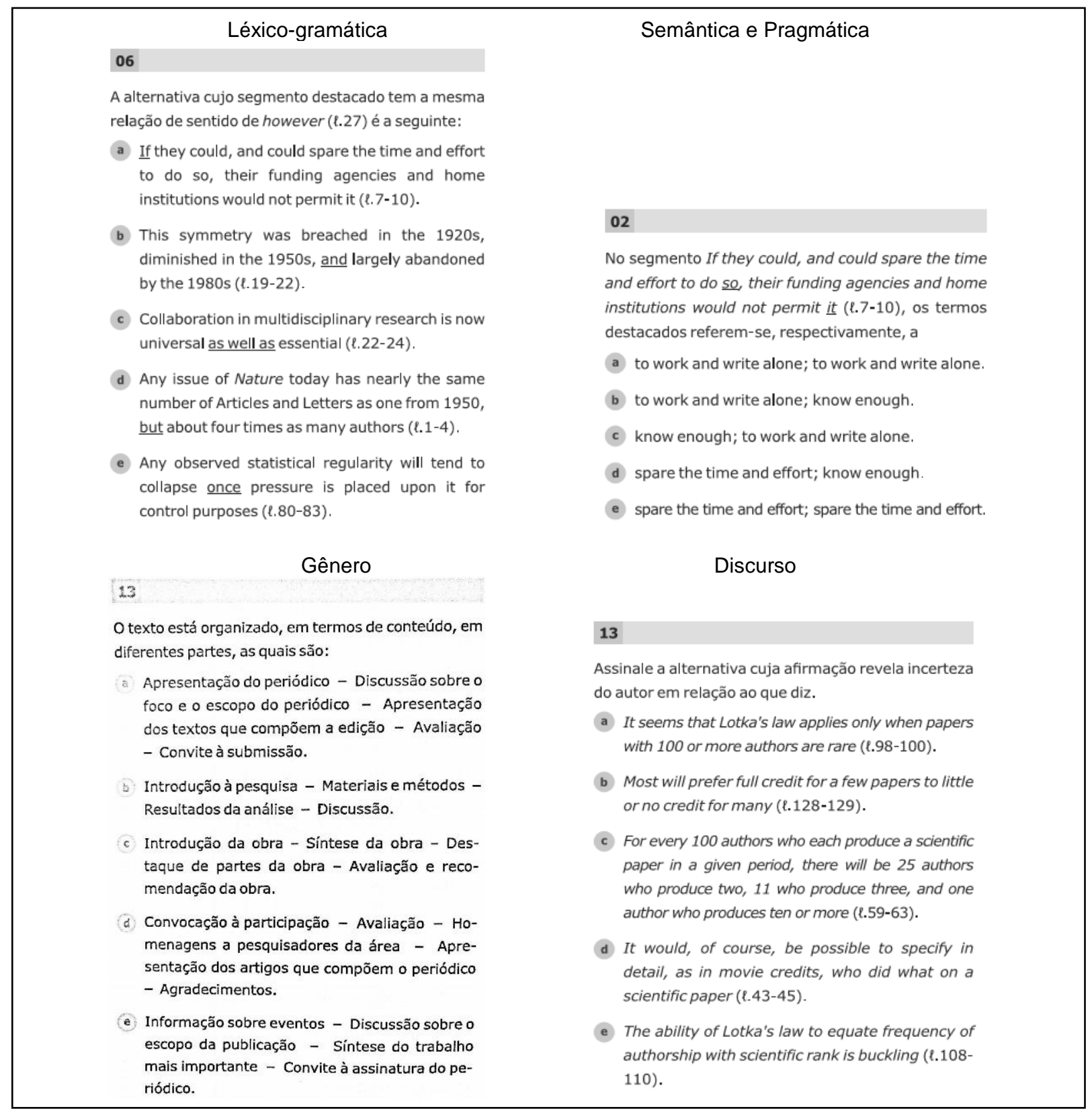

Quadro 3: Estratos da linguagem nas questões.

Fonte: questões do TESLLE, edições de 2014, 2015 e 2016. 
Para chegar nesse resultado, consideramos quais aspectos da linguagem foram requisitados pelas questões, isto é, quais aspectos da linguagem os examinandos deveriam reconhecer. Consideramos que as questões que abordam o estrato da Léxico-gramática são as que se referem às orações e aos complexos oracionais, e a aspectos gramaticais como advérbios e tempos e vozes verbais. As questões dentro do estrato da Semântica e Pragmática referem-se ao significado, portanto, elas abordam evidência textual, referência, inferência, figura de linguagem, funções de partes do texto, tradução e multimodalidade. As questões que abordam aspectos de gênero foram classificadas dentro do estrato de Gênero. No estrato do Discurso, consideramos as questões que abordam os níveis de comprometimento do autor em relação a que ele/ela está afirmando.

Os resultados apontam que 71\% das questões abordam o estrato da Semântica e Pragmática. O estrato do Discurso representa 13\% das questões. O estrato da Léxico-gramática representa 12\% das questões, e 4\% das questões abordam o estrato do Gênero. Portanto, pode-se perceber que o TESLLE apresenta a Semântica e Pragmática como o aspecto da linguagem mais usado no processo da leitura, seguido do Discurso, Léxico-gramática e Gênero. O Quadro 4 sistematiza os estratos da linguagem e os enfoques relacionados com esses estratos.

\begin{tabular}{|c|c|}
\hline Estratos & Enfoques das questões \\
\hline Discurso & Modalidade \\
\hline Gênero & Gênero \\
\hline \multirow{7}{*}{$\begin{array}{l}\text { Semântica e } \\
\text { Pragmática }\end{array}$} & Evidência textual \\
\hline & Referência \\
\hline & Inferência \\
\hline & Figura de linguagem \\
\hline & Funções de partes do texto \\
\hline & Multimodalidade \\
\hline & Tradução \\
\hline \multirow{3}{*}{ Léxico-gramática } & Relações oracionais \\
\hline & Tempos e vozes verbais \\
\hline & Advérbios \\
\hline
\end{tabular}

Quadro 4: Relação entre estratos da linguagem e enfoques das questões.

Fonte: produzido pelas autoras.

Observa-se que, em quatro edições, o estrato da Semântica e Pragmática envolve o mesmo número de questões, e somente nas edições de 2014-2 e 2015-2 há uma questão a mais que aborda esse estrato. Em quatro edições, ele representa 68\% das questões, e, nas edições 2014-2 e 2015-2, representa 75\% das questões. Considerando que a maioria das questões aborda o estrato da Semântica e Pragmática, podemos confirmar que o TESLLE realmente testa se o examinando entende o sentido do texto que precisa ser lido, e se ele/ela consegue ler satisfatoriamente um texto acadêmico publicado em uma língua estrangeira.

Podemos identificar que a relação entre texto/contexto é explorada no TESLLE, pois, ao explorar quatro dos seis estratos da linguagem, o teste demanda que os examinandos entendam mais que aspectos gramaticais. Para responder às questões, os examinandos precisam identificar a posição do autor em relação aos pontos de vista apresentados, além do propósito comunicativo ou os movimentos retóricos do gênero. Também precisam entender a coesão e coerência do texto ao identificar os referentes de pronomes; fazer inferências para compreender partes específicas do texto; compreender linguagem metafórica, as funções que 
diversas partes do texto exercem, e a relação entre texto verbal e não-verbal, conhecimentos que exploram os diversos níveis da linguagem. Assim, o TESLLE demonstra a visão de linguagem conectada ao contexto de uso. Para ler satisfatoriamente, o examinando precisa entender essa conexão.

\section{CONSIDERAÇÕES FINAIS}

A análise mostrou que o TESLLE realmente testa a habilidade de leitura do examinando, pois a maioria das questões explora o nível da Semântica e da Pragmática, em que os examinandos devem acionar conhecimentos tipicamente relacionados à habilidade de leitura de textos, como identificar processos de referenciação no texto, fazer inferências etc. Além disso, o TESLLE adota uma perspectiva de leitura que entende a linguagem como um todo de significado, uma vez que aciona quatro estratos da linguagem nas suas questões (Discurso, Gênero, Semântica e Pragmática e Léxico-gramática) e não apenas um dos estratos mais relacionado com a habilidade de leitura (Semântica e Pragmática). Ao adotar a visão de linguagem conectada ao contexto, o TESLLE demonstra que, para ler em uma língua estrangeira, o examinando precisa entender o texto como uma "[...] prática situada e não como sistema de regras e verdades [...]" (MOTTA-ROTH, 2008, p. 375). Isso significa que ele precisará lidar com a função e a organização do gênero proposto para a leitura; com quem o escreveu, os propósitos e o público-alvo; e com o tópico/assunto do texto. A perspectiva de linguagem que subjaz o TESLLE é a "linguagem como gênero", uma vez que o texto-base das questões é apresentado da mesma forma como circula nas práticas sociais, ou seja, com a mesma extensão e o mesmo layout. Além disso, parece ser o texto-base que orienta a elaboração das questões, ao invés de haver questões estritamente gramaticais desconectadas do propósito comunicativo dos textos.

\section{REFERÊNCIAS}

BECKER, L. W. EFL Reading patterns: a study based on Teste de Suficiência at the Federal University of Santa Maria. 2013. 19f. Trabalho Final de graduação (Curso de Graduação em Letras Português-Inglês) - Universidade Federal de Santa Maria, Santa Maria, RS, 2013.

BONINI, A. Critical genre analysis and professional practice: the case of public contests to select professors for Brazilian public universities. Linguagem em (Dis)curso, v. 10, p. 485-510, 2010.

CUNHA, A. C. S. The reading perspective of TESLLE: the English Reading proficiency test of UFSM. 2015. 19f. Trabalho Final de Graduação (Curso de Graduação em Letras Inglês) - Universidade Federal de Santa Maria, Santa Maria, RS, 2015.

FAIRCLOUGH, N. Language and power. London: Longman, 1989.

FAIRCLOUGH, N. Media discourse. London: Edward Arnold, 1995.

FAIRCLOUGH, N. Critical discourse analysis. 2. ed. Harlow, UK: Pearson, 2010.

HALLIDAY, M. A. K. Language as social semiotic: the social interpretation of language and meaning. London: Edward Arnold, 1978.

HALLIDAY, M. A. K.; HASAN, R. Language, context, and text: aspects of language in a social-semiotic perspective. Oxford: Oxford University Press, 1989. 
HENDGES, G. R. A genre and register analysis of electronic research articles from a systemic functional perspective: new medium, new meanings. PHD project. Florianópolis: PPGI/UFSC, 2005.

HUGHES, A. Teaching and testing. In: HUGHES, A. Testing for language teachers. Cambridge: Cambridge University Press, 1997. p. 1-5.

MARCHEZAN, M. T. N. Perfil de provas elaboradas por professores de inglês na escola pública fundamental. 2005.163 f. Tese (Doutorado em Letras) - Universidade Federal do Rio Grande do Sul, Porto Alegre, RS, 2005.

MARCUZZO, P. Uma análise do teste de Suficiência em Leitura em Língua Inglesa da UFSM. Santa Maria: Universidade Federal de Santa Maria, 2016 (Projeto de Pesquisa).

MARTIN, J. R. English text: system and structure. Philadelphia/Amsterdam: John Benjamins, 1992.

MEDEIROS, E. B. Provas objetivas: técnicas de construção. Rio de Janeiro, FGV. 1977.

MOTTA-ROTH, D. Questões de metodologia em análise de gêneros. In: KARWOSKI, A. M.; GAYDECZKA, B.; BRITO, K. S. (org.). Gêneros textuais: reflexões e ensino. Palmas: Kaygangue, 2005. p. 179-202.

MOTTA-ROTH, D. Análise crítica de gêneros: contribuições para o ensino de linguagem. D. E. L. T. A., São Paulo, v. 24, n. 2 , p. 341-383, 2008.

MOTTA-ROTH, D.; HEBERLE, V. A short cartography of genre studies in Brazil. Journal of English for Academic Purposes, n.19, p. 22-31, 2015.

MOTTA-ROTH, D.; MARCUZZO, P. Ciência na mídia: análise crítica de gênero de notícias de popularização científica. Revista Brasileira de Linguística Aplicada, v. 10, n. 3, p. 511-538, 2010.

NASCIMENTO, R. G. Análise crítica de gênero, planejamento de material didático e letramentos do professor de inglês como língua estrangeira/adicional. In: TOMITCH, L. M. B.; HEBERLE, V. M. (org.). Perspectivas atuais de aprendizagem e ensino de línguas. Florianópolis: LLE/PPGI/UFSC, v. 1, 2017. p. 121-152.

SOARES, V. A. de S. F. Análise crítica de gênero e o exercício de leitura da palavra mundo: diálogos possíveis. Revista Brasileira de Linguística Aplicada, v. 16, n. 3, p. 335-364, 2016.

TESLLE. Teste de Suficiência em Leitura em Língua Estrangeira. 2018a. Disponível em: http://w3.ufsm.br/testedesuficiencia/index.php. Acesso em:20 jun. 2019. 
TESLLE. Editais. Disponível em: http://w3.ufsm.br/testedesuficiencia/index.php/editais. 2018b. Acesso em: 20 jun. 2019.

TESLLE. Minimanual do candidato. 2018c. Disponível em: http://w3.ufsm.br/testedesuficiencia/images/Mini manual do candidato TESLLE_2018.pdf. Acesso em:20 jun. 2019.

UNIVERSIDADE FEDERAL DE SANTA MARIA. Resolução $\mathrm{n}^{\circ}$ 003/10. Disponível em: http://w3.ufsm.br/ppggeo/images/resolucao\%20003 2010.pdf. Acesso em: 25 jun. 2017.

WIELEWICKI, H. G. Testagem de proficiência em leitura em inglês: examinandos e teste como fontes de entendimento sobre esse processo. 1997. 199f. Dissertação (Curso de Pós-Graduação em Letras) - Universidade Federal de Santa Maria, Santa Maria, 1997.

WIGGINGS, G. P. Introduction: assessment and the morality of testing. In: WIGGINGS, G. P. Assessing student performance: exploring the purpose and limits of testing. San Francisco: Jossey-Bass Publishers, 1993. p. 1-33.

\section{(c) (i) $\odot$}

Recebidoem 28/07/2018. Aceito em 29/11/2018. 